\title{
Archéopages
}

Archéopages Archéologie et société

40 | 04-07/2014

Villages

\section{Des qanàts en Gaule Narbonnaise}

Roland Haurillon

\section{(2) OpenEdition}

Journals

Édition électronique

URL : https://journals.openedition.org/archeopages/657

DOI : 10.4000/archeopages. 657

ISSN : 2269-9872

\section{Éditeur}

INRAP - Institut national de recherches archéologiques préventives

\section{Édition imprimée}

Date de publication : 1 juin 2015

Pagination : 168-169

ISSN : 1622-8545

\section{Référence électronique}

Roland Haurillon, « Des qanàts en Gaule Narbonnaise », Archéopages [En ligne], 40 | 04-07/2014, mis

en ligne le 01 juillet 2016, consulté le 29 janvier 2022. URL : http://journals.openedition.org/ archeopages/657 ; DOI : https://doi.org/10.4000/archeopages.657 
développement, le site ne fournit plus, ou peut-être pas assez pour être perceptibles, de rejets permettant de prolonger son occupation au $\mathrm{II}^{\mathrm{e}}$ siècle, voire même au $\mathrm{III}^{\mathrm{e}}$ siècle de notre ère. Pour illustrer ces périodes, on ne dispose plus de structures en creux, ces pièges à artefacts que sont les fosses d'extraction de matériaux ou les tranchées d'implantation de constructions.

L'examen des céramiques issues des puits présente une image bien différente sur la chronologie de l'occupation. On y rencontre surtout du matériel en usage au $\mathrm{II}^{\mathrm{e}}$ siècle et encore au $\mathrm{III}^{\mathrm{e}}$ siècle de notre ère [ill. 1b]. Une opération archéologique menée sans la fouille des puits nous aurait probablement conduits à envisager un abandon précoce du site au profit de la villa de la Domergue. Ce grand domaine est établi à moins de $1 \mathrm{~km}$ au nord et son occupation se prolonge jusquà la fin de l'Antiquité. La situation paraît plus complexe si l'on envisage comme possible le maintien d'une occupation et d'activités plus discrètes sur le site.

La fouille des puits de la Lesse permet d'illustrer les problèmes de taphonomie que l'on peut rencontrer à la surface des sites et d'apporter des nuances sur les modèles d'implantation et de disparition des habitats ruraux antiques.

\footnotetext{
Références bibliographiques

POMARÈDES H. (DIR.), 2011, Implantation d'une ferme pré-augustéenne et développement d'une petite villa de la cité de Béziers (fin $I^{e r}$ s. av. /III $s$. ap. J.-C.), La Lesse, Sauvian (Hérault), Rapport final d'opération, Inrap Méditerranée, 377 p.
}

Des qanàts en Gaule Narbonnaise

Roland Haurillon, Inrap

Avec l'intervention de l'association Archéopuits, une équipe de l'Inrap a pu étudier trois puits antiques au nord-est de Béziers (Hérault) (Haurillon et al., 2011 et 2012 ; Haurillon, 2012). Situés en contexte rural, hors habitat, carrés ou circulaires, parfois bâtis, ils ont une profondeur de 5,10 et $11,5 \mathrm{~m}$. Grâce à leur fouille exhaustive, nous avons pu mettre en évidence leur relation avec des galeries drainantes souterraines appartenant à trois réseaux différents.

Le milieu hydrogéologique local est propice à la formation de petits aquifères. Pour récupérer cette précieuse ressource, les Romains utilisent un système d'exploitation en puits-galerie. Le procédé consiste à creuser à la sape un tunnel quasi horizontal à partir de puits verticaux alignés et équidistants. Les nappes perchées sont alors traversées par certains de ces puits (puits-mères) dont l'eau est récupérée par ladite galerie. La récolte se fait donc ici par captage, mais également par percolation [ill. 1]. En effet, la galerie souterraine draine aussi l'eau contenue dans l'aquifère gréseux dans laquelle elle a été creusée. Cette eau exsude sous forme de fines gouttelettes le long des parois. C'est la récolte des «larmes» ou «pleurs de terre», expression utilisée dans la littérature archéologique du XVIII ${ }^{\mathrm{e}}$ siècle pour décrire ce phénomène déjà observé dans d'autres ouvrages mal datés, au nord de Béziers (Sabatier, 1854). L'eau est ensuite acheminée par une rigole aménagée à la base de la galerie souterraine, jusquà une vaste citerne enterrée. Un tel stockage d'appoint permet ainsi d'alimenter certaines activités domestiques, agricoles ou artisanales.

Ce système hydraulique reconnu sur le territoire de Béziers est analogue à des ouvrages recensés sur tout le pourtour méditerranéen (Goblot, 1979). Ils portent le nom de « qanàt». Si le milieu scientifique s'accorde à lui donner une origine eurasienne qui remonterait au $\mathrm{I}^{\mathrm{er}}$ millénaire avant notre ère, ce savoir-faire serait encore plus ancien puisqu'il hériterait de techniques minières. Quelques ouvrages similaires ont été étudiés, principalement en Gaule Belgique (Kayser, Waringo, 2003; Boulanger, 2009). Cependant, c'est la première fois que la fouille d'une série de puits met en évidence l'utilisation de cette technique en Gaule Narbonnaise. Associées à celles présentées dans cette rubrique, ces découvertes biterroises confirment l'intérêt d'une collaboration avec Archéopuits, dans le cadre de ce type d'intervention archéologique. Elle doit bien évidemment être stimulée par une volonté scientifique pour faire aboutir une réflexion ouverte sur la problématique de ces ouvrages. 


\section{Références bibliographiques}

BOULANGER K., 2009, Les «qanàts » gallo-romains de Lorraine, in C. Aradie-Reynal, S. Provost et P. VIPARD (DIR.), Les Réseaux d'eau courante dans l'Antiquité: réparations, modifications, réutilisations, abandon, récupération, Rennes, Presses universitaires de Rennes, p. 133-144.

Gовцот H., 1979, Les Qanàts, une technique d'acquisition de l'eau, Paris, Mouton, 1979.

Haurillon R., Court-Picon M., Femenias J.-M., Figueral I., Forest P., Pallier C., Rascalou P. et TARDY C., 2011, L'Ouvrage hydraulique souterrain de Mazeran: aqueduc, qanàt ou qanàtqueduc? Béziers (34), Autoroute A75 Section Béziers-Pézenas, Rapport final d'opération, Inrap Méditerranée, $208 \mathrm{p}$.

Haurillon R., Bruxelles L., Femenias J.-M. Figueral I., Forest V., Mignot O., Pallier C., Rascalou P. et TARDY C., 2012, Techniques hydrauliques antiques oubliées ou disparues. L'exemple des galeries drainantes souterraines de Béziers (34) et l'adduction en conduite forcée par sextuple siphon inversé de Causses-et-Veyran (34). Opération ZAC de Mazeran, Tranche 1, lieu-dit "Le Garissou », Rapport final d'opération, Inrap Méditerranée, $128 \mathrm{p}$.

HAURILlON R., 2012, «Découverte d'une galerie drainante souterraine d'époque romaine à Béziers (34) », Subterranea, 164, p. 115-123.

KAYSER P., WARINGO G., 2003, «L'aqueduc souterrain des Raschpëtzer, un monument antique de l'art de l'ingénieur au Luxembourg ", Revue archéologique de l'Est, 52, p. 429-444.

SABATIER E., 1854, «Histoire de la ville et des évêques de Béziers », Bulletin de la Société archéologique, scientifique et littéraire de Béziers.

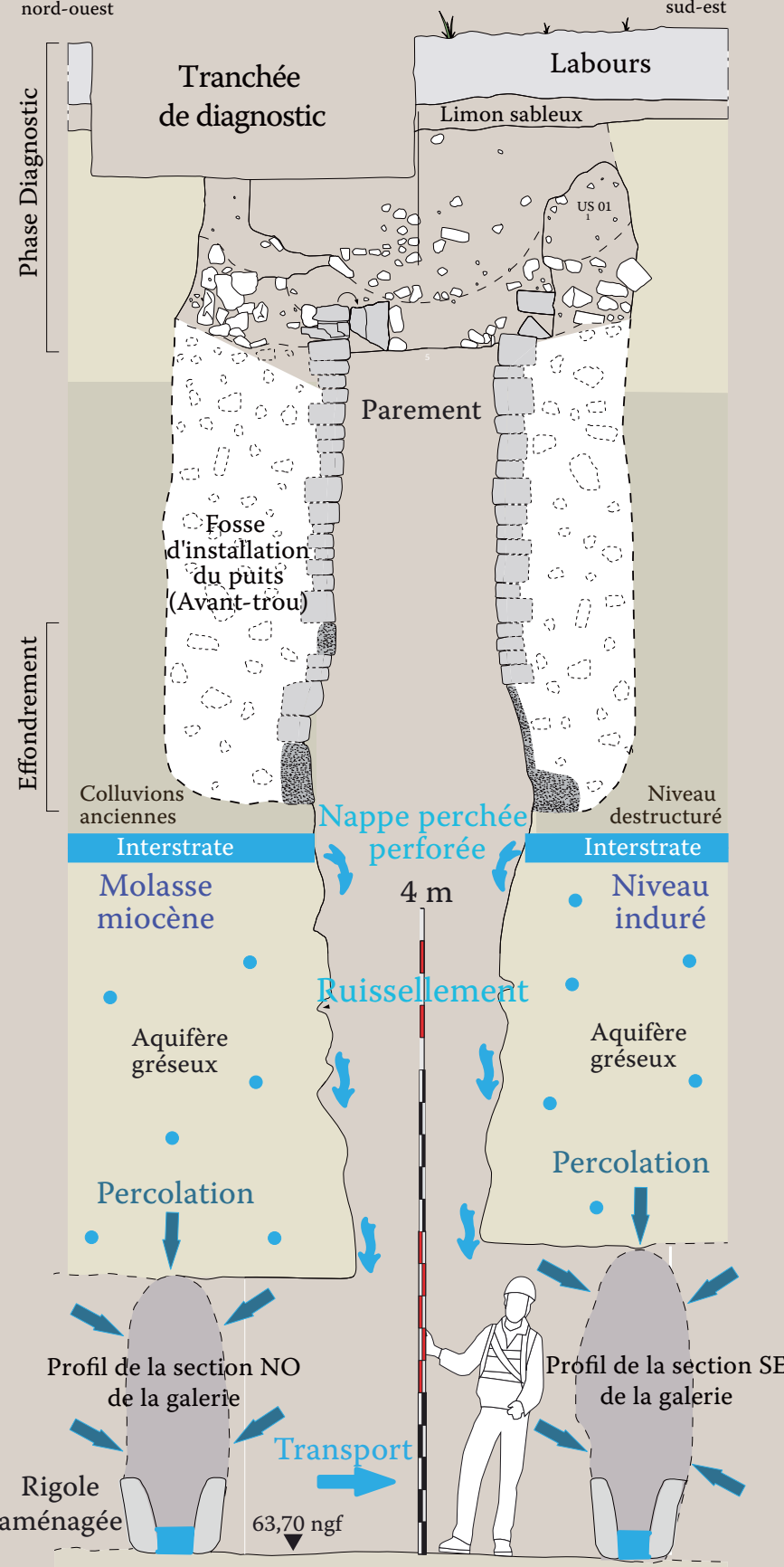

